\title{
Designing Training Activities for a New PhD Program in Engineering Education
}

\author{
David Lopez \\ Institute of Education Sciences \\ Universitat Politècnica de Catalunya \\ Barcelona, Spain \\ david@ac.upc.edu
}

\begin{abstract}
This research paper for the practice of work-in-progress presents the training activities designed for students of a new PhD program in Engineering Education. These activities are based on the study of the training courses of five Engineering Education PhD programs, and on the literature concerning PhD training challenges. A set of competencies to be acquired is first defined; then the training activities are designed by means of a SPOOC (Self-Paced Open Online Course) in order to guide the acquisition of these competencies. The SPOOC is currently under design, taking an initial cohort of 9 students as an experimental group.
\end{abstract}

Keywords—Engineering Education, PhD programs, Engineering Education Research.

\section{INTRODUCTION}

This research paper for the practice of work-in-progress presents the training activities designed for students of a new $\mathrm{PhD}$ program called "PhD Program in Engineering, Science and Technology Education" whose first cohort began in September, 2020.

The Field of Engineering Education (EngEd) is a relatively new discipline that has begun to be perceived as an emerging field of scientific research [1][2]. In 2007, Borrego [3] published a study describing five conceptual difficulties engineering faculties face when learning about rigorous research in EngEd. Although some EngEd departments has been formed since then, and new degrees in EngEd have appeared [4][5], most researchers in EngEd have evolved from their own engineering fields of knowledge, with no well-established EngEd communities in their universities, and therefore face a difficult path to becoming EngEd researchers [6]. Furthermore, some uncertainty still exists about what constitutes quality research in EngEd [7][8][9] and about how to promote international collaboration by developing an internationally connected field of inquiry [10][11][12].

Nevertheless, as the field of knowledge has gained maturity, a new generation of professionals and researchers with interests in EngEd has also emerged. These professionals retain a technical area of expertise while also focusing on the pedagogy of their discipline, so they can study the teaching-learning process in their field of knowledge. There is a consensus that rigorous and indepth research in EngEd is necessary, and some universities around the world have started research departments and doctoral programs. Despite this interest, there are only a few $\mathrm{PhD}$ programs in the area worldwide. According to the Engineering Education Wiki ${ }^{1}$, there are about $40 \mathrm{PhD}$ programs in EngEd in the world, the oldest being that established in 2004 at Purdue University. In the European Higher Education Area (EHEA), to which our university belongs, there are only three programs, those of Aalborg University, Chalmers University of Technology and Uppsala University. While there are some EngEd departments in Europe, to our knowledge they have no explicit PhD programs in EngEd. This is the case of KTH Royal Institute of Technology, Linköping University or Dublin Institute of Technology.

Several challenges arise when creating a new $\mathrm{PhD}$ program in EngEd, one of which is the design of training courses. The training organization and the context in which the activities take place have an enormous impact, not only in the acquisition of knowledge and research methodologies, but also on the acquisition of the sense of belonging to a community, autonomy to become a researcher, academic identity, and other factors that greatly influence the decision to pursue doctoral studies. In order to design our training activities, we started by comparing five programs with the aim of identifying common ideas on learning outcomes and courses that might help us to formulate our own design, with the finding that the programs are consistent in terms of training needs. In this paper, we present the training activities designed for our PhD program, taking into account both the previous research and the special characteristics of our case.

Most EngEd programs advise their students to enroll in foundations of education courses, usually in their own Education Schools. Since we are a technical university that only offers degrees in engineering, architecture and sciences, we have no schools or departments of psychology or education. Given such a scenario, we asked ourselves if we could organize a non-classical training program using the learning foundations and techniques that we wanted our students to acquire. After all, we are training engineers in a $\mathrm{PhD}$ EngEd program, so why not use the training itself as an example of EngEd theories and methods?

\footnotetext{
${ }^{1}$ A resource created by the ASEE's Student Division and the Center for Engineering Learning and Teaching. http://engineeringeducationlist.pbworks.com/w/page/27578912/Engineering\%20Education\%20Community\%20Resource
}

(C) 2021 IEEE. Personal use of this material is permitted. Permission from IEEE must be obtained for all other uses, in any current or future media, including reprinting/republishing this material for advertising or promotional purposes,creating new collective works, for resale or redistribution to servers or lists, or reuse of any copyrighted component of this work in other works. 
To that end, we first defined a set of competencies to be acquired in the $\mathrm{PhD}$ program. The training activities are currently designed as a SPOOC (Self-Paced Open On-line Course). The training pack can be adapted to each student according to his/her background and research interest, with the help of advisors and a small group of experts. The SPOOC is at present in the design stage, using our first cohort of 9 students as an experimental group.

\section{CURRENT SITUATION IN OUR ENVIRONMENT}

\section{A. PhD training programs in our country}

Spain adapted its higher education program, in particular $\mathrm{PhD}$ studies, to the EHEA (European Higher Education Area) during the first decade of the $21^{\text {st }}$ century. The current general requirement for enrollment in a doctoral program is to have passed 300 ECTS, 60 of them obtained in a master's degree. Each doctoral program contains a list of degrees that allow access to that particular doctorate, either directly (having passed a specific master's degree, called 'reference master') or by taking some subjects belonging to the reference master's degree. On the other hand, there are no mandatory courses in the PhD programs, but each university has a Doctorate School which offers voluntary courses. The training that each doctorate program can offer its students therefore consists of a series of subjects from the reference master that must be taken before enrolling in the doctoral program, with the recommendation that students enroll in some of the courses offered by each Doctorate School (such as Research Methodologies, Statistics, etcetera).

\section{B. Our university situation}

Our university, the Universitat Politècnica de Catalunya, only offers degrees in engineering, sciences and architecture. We have no schools or departments of psychology or education, and neither does our faculty have a tradition of social science methods. However, our university has a Master Degree in Education for Secondary School and Vet Studies. In Spain, it is mandatory to hold this degree in order to be employed as a Secondary or Vet teacher, and each university offers this degree in its own specialties. In our case, the Master Degree is aimed at teachers of technology and sciences subjects, and constitutes our $\mathrm{PhD}$ program's reference master.

While it may seem contradictory that a technological university such as ours, with little tradition in education, intends to create a PhD program in this field, the fact is that the universities leading the way in EngEd are precisely technological universities. This is hardly surprising when one considers that research in education in each discipline must be guided by experts in that discipline. Boyer [13] defined the scholarship of teaching and learning as the study of the teaching-learning processes of each discipline, while Bruner [14] argued that quality teaching requires in-depth knowledge of the difficulties and peculiarities of learning in a certain discipline. This is why specialists with a deep knowledge of the epistemology of that discipline are required, and who have also been trained in educational aspects, thereby enabling them to study the teaching-learning process in their own field of knowledge.

Our university is one of the leading Higher Education Institutions in Europe in the field of engineering and technology, and is also one of the top HEIs in the number of papers published in EngEd [15]. It is therefore perfectly reasonable that a doctoral program should emerge in our university. Nevertheless, given the way $\mathrm{PhD}$ training programs are designed in Spain, we have no courses on research methods in social sciences, or a master degree in education where our students might learn the fundamentals in education. However, rather than regarding this situation as a problem, we seized upon it as an opportunity to develop a novel training program for our students by designing it from scratch.

\section{BACKGROUND AND PREVIOUS WORK}

\section{A. EngEd PhD training programs}

The first step was to study other PhD programs at EngEd. The programs analyzed were the three offered at the EHEA (Aalborg, Chalmers and Uppsala) and two of the oldest in the USA (Purdue and Virginia Tech). The results of this study have been previously published [16]. We found that the five programs are consistent in terms of the training needs they seek to cover.

All programs insist on the importance of training in Foundations of Engineering Education, including theoretical methods, the ability to conduct effective and rigorous research, with special emphasis on qualitative and qualitative research, mixed methods, and so on. All the programs include courses on generic competencies, such as writing research papers, or values in society and research. Some programs provide courses on engineering knowledge in an engineering field other than EngEd. Finally, a common trend of all the programs is that they provide a flexible, tailored organization for each student according to his/her ow interests and goals.

\section{B. Current research in PhD training programs}

The need to rethink doctoral studies has long been recognized in the community, and we identified several drawbacks in $\mathrm{PhD}$ training in the literature. One of the challenges of doctoral programs is balancing the need for support and student autonomy: advisors should provide guidance for students to acquire competencies, while also providing them with the autonomy required to become confident and independent researchers [17].

The study by Ferguson, Hovey and Henson [18] indicates that doctoral students in education "often come to their doctoral program without a strong grounding in scientific methods (... it) requires graduate programs to introduce students to scientific research". Kittur and Brunhaver [19] indicate that much of engineering research is still being conducted by researchers with a background in traditional engineering disciplines, but without formal training in EngEd research methods. 
Since the beginning of the 2000s, it is commonly accepted that the decision to undertake doctoral studies depends on various individual, interpersonal and contextual factors, including supervision, competencies to be developed, and the influence of the social environment [20]. It is widely reported in the literature that $\mathrm{PhD}$ students undergo considerable pressure, solitude, uncertainty and stress, which may lead to depression and anxiety [21]. There are many factors that must be considered, both internal (motivation, academic identity, self-regulatory strategies, writing skills) and external (supervision, financial support opportunities, personal/social lives) [22].

In recent years, there has been an increase in accounting and efficiency in doctoral studies, especially in the idea of completing the doctorate in a limited time (usually between 3 and 4 years). This pressure in accounting is leading to a greater importance given to the product of the doctorate (the dissertation and published papers) than to the formation of the identity of the student as a researcher [23]. However, the focus on doctoral education in current research is shifting from the 'PhD as a product' to 'PhD as a process' [24], as the notion of 'becoming peer' has more meaning for students than becoming an 'independent researcher' [20] [23].

In this design phase of our training program, it is necessary to decide on exactly what we should focus. The literature indicates that intellectual abilities and knowledge alone are not sufficient to complete doctoral studies successfully [20]; the training organization and the context and conditions in which doctoral studies take place have an enormous impact on the process [25]. Breitenbach [26] indicates that the perception of usefulness of the curriculum and instruction is a key factor, especially in PhDs with a strong online component. Ways of organizing instruction in a more structured way have been studied, such as the Ewing(C) model "characterized by a highly structured, sequential curriculum; intense facilitation and dialogue; collaborative learning within a cohort model; and performance-based assessment of core research competencies" [27]. Therefore, we decided to focus on common problems reported in training programs.

\section{ORGANIZATION}

\section{A. A program based on competencies}

Since the Bologna process, bachelor and master degrees in Europe are based on competencies rather than on knowledge. Despite this fact, doctoral studies are not usually defined by competencies, at least in our environment. We have organized our doctorate according to competencies that should be acquired, as is done in models such as those of Durette, Fournier and Lafon [24] or Ewing et al [27]. In our model, we decided to divide them into Foundational Competencies (which all PhD holders should master) and Specialized Competencies (dependent on every specific program). After analyzing and discussing the literature, seven foundational competencies (F) and three specialized competencies (S) were chosen as those to be acquired in our doctoral program, a description of which is given below:

- Innovation and creativity (F1): The ability to generate ideas, move from design to implementation creating solutions. Ability to propose new approaches to existing problems or pose new problems, connecting ideas and proposals, with flexibility and resilience, adapting to circumstances.

- Information management (F2): The ability to search and relate information, recognize reliable sources, compare information critically, and justify in a well-founded manner the assumptions made in one's own research.

- Experiment design, analysis and interpretation of data (F3): Ability to analyze facts, situations or problems in a reflective, rational and subjective way, conducting an analysis without biases based on evidence, which leads to an informed and reasoned judgment. Ability to design and conduct appropriate experiments, analyzing and interpreting data to generate conclusions. Ability to create a reasoned and complete investigation plan.

- Communication of research results (F4): The ability to communicate both in writing (in articles, reports or thesis) and orally (in conference presentations or defense of articles or thesis) the results of one's own research, adapted to the available media and to a wide range of audiences, with special emphasis on audiences composed of experts.

- Teamwork (F5): The ability to function effectively in a research team (preferably multidisciplinary and multicultural), creating a collaborative and inclusive environment, with the ability to manage time, leadership, effective communication within the team, establish objectives and tasks, and fulfill them with responsibility towards the team.

- Ethics (F6): The ability to show ethical behavior as a researcher, as well as to know the ethical implications in the development of an investigation and the ethical consequences that could be derived from it.

- Autonomy and sense of belonging (F7). The ability to work unsupervised and undirected, to experience choice and volition in one's actions, having at the same time the feeling of being a peer within the world of research.

- Epistemology of STEAM education (S1): The ability to develop a solid theoretical framework for tackling a problem or situation in a STEAM education environment, based on educational theories and the epistemology of the area of knowledge in which the problem arises, developing reasoned and coherent research questions with the existing knowledge.

- Design of a research in STEAM education (S2): The ability to design and conduct research in STEAM education, using the most appropriate methods and methodologies, given the research questions, and conducting scientific, ethical and evidence-based research that leads to reasoned and unbiased conclusions. 
- Practice and products of engineering and science (S3): Knowledge of the basic principles of complex problems faced in the world of engineering, science and technology, and how these problems are identified, formulated and solved on the basis of these areas of knowledge.

\section{B. Materials and tools for students}

The training program is organized as a SPOOC (self-paced open online course). The idea is to offer students a series of resources together with a general guide on how to conduct their research. With the help of the guide and the advisors and experts in each competency, the students will be able to develop the competencies proposed herein.

Students are encouraged to begin by defining their own topics of interest. According to the chosen topics, a suitable advisor is assigned and the investigation can start.

The first documentation that students receive is on how to pose research questions and how to develop a state of the art. Students should start by reading literature on the subject they choose to work on and formulate some initial questions (still very basic), always with the guidance of the advisor.

In parallel to reading articles related to their research topic, students are encouraged to read about the foundations of education and research methodologies in STEAM education in selected chapters from the books by Coe et al [28], Cohen et al [29], Creswell and Guetterman [30], Heywood [31], Johnson et al [32], Patton [33] and Tight [34].

These readings are intended to familiarize students with the basic concepts required in the program. Once acquired, students must write a report indicating the most appropriate methodology for conducting the research work proposed and for defending it before the board of advisors. Once the proposal is accepted, a list of research papers and dissertations employing the proposed methodology will be recommended to the student. This is what defines the course as self-paced, since students can advance at their own pace, making decisions and receiving training adapted to the needs of their research.

The training is complemented by courses on statistical tools, on how to write a research article or how to defend a paper in a conference, to name a few. These courses are online and asynchronous.

During the years devoted to the completion of the doctorate, students must present a set of documents. In the first year, they are required to present an initial state-of-the-art proposal, some initial research questions, the report on the methodology to be developed and a time frame for the activities. In the following years, a report on the evolution of the research must be presented annually, and must include the evolution of the research as well as a description of what paths the research is opening up. However, this will not form part of their final dissertation, indicating how the student as an advisor should organize a thesis on topics that will not be included in that dissertation.

There is one last point that is subject to evaluation: in addition to the previously mentioned master in education, we also have a postgraduate degree in STEAM education as part of the training program offered to our lecturers. We want our doctoral students to get involved in the final master and postgraduate theses of these degrees in the topics closest to their own research, and always acting as a co-advisor with the collaboration of another experienced professor.

All the aforementioned documents, together with the papers and reports produced by the student, will form part of each student's portfolio, on the basis of which the board of advisors will evaluate the acquisition of competencies. The information in this portfolio will be used to recommend to each student the activities that are considered necessary for the full acquisition of skills.

\section{DISCUSSION}

The training design is based on competencies, Competency being defined as the sum of Knowledge, Skills and Dispositions. With regard to Knowledge, especially at the doctoral level, it may be more interesting to acquire it by reading the relevant literature than by conventional courses. The most important target is the acquisition of Skills and Dispositions, which is what has guided the design of the program.

The evidence to present includes the courses followed, the different reports sent, and the articles published, which will enable verification of the acquisition of competencies related to information management, design, analysis and interpretation of experiments, communication of results, ethics knowledge. of the epistemology of STEAM education and design of a research in STEAM education (F2, F3, F4, F6, S1 and S2).

The novelty of this proposal resides in certain key points. First, due to the training guided by the interests and needs of the students themselves, it will have an impact their autonomy (F7). The delivery of the annual report containing a description of the paths opened up by the research, together with an outline of how students would continue research work on these topics, even if they do not form part of their theses, will assist them in their autonomy, innovation, creativity and design of a STEAM research project (F1, F7, S2). Finally, their participation as advisors in a master or postgraduate thesis will have an impact on the competencies of innovation, creativity, teamwork and sense of belonging, as well as on the epistemological bases and research design in STEAM (F1, F5, S1, S2).

The only competency for which there is no designed training is S3 (practice and products of engineering and science), because it is currently mandatory to hold a bachelor or master degree in engineering or science in order to enroll in the doctorate program. Therefore, it is assumed that our students will have become proficient in this competency. However, in the future it is our intention that students from other fields of knowledge will enroll in our program (for example, psychologists, educators, linguists, ...), 
based on the assumption that their objective is to conduct research in science and engineering education. When these new students undertake the $\mathrm{PhD}$ program, they will be required to undergo training in this competency.

\section{CONCLUSIONS}

The design of a training program for a $\mathrm{PhD}$ in engineering education is presented in this paper. The proposal is based on the study of other similar PhD programs, but adapted to the special circumstances of our university and including some novel activities. There are no traditional doctoral courses in this proposal, but rather a SPOOC guided by the interests and needs of each student. The program is based on the acquisition of 10 competencies, defined by taking into account the drawbacks in of the $\mathrm{PhD}$ training programs found in the literature. The acquisition of competencies will be evaluated by evidence, using a portfolio.

The training program is currently under development with an initial cohort of $9 \mathrm{PhD}$ students. These students are currently receiving personalized training, but it is a very expensive system that must be reorganized in the future for the inclusion of many more students. Student feedback on the SPOOC in development will allow us to fine-tune it.

\section{REFERENCES}

[1] J. Lohmann and F. Froyd. "Chronological and ontological development of engineering education as a field of scientific inquiry". In Second Meeting of the Committee on the Status, Contributions, and Future Directions of Discipline-Based Education Research, Washington, DC. 2010. https://doi.org/10.1017/CBO9781139013451.003

[2] R. A. Streveler, and K.A. Smith. "Rigorous research in engineering education". Journal of Engineering Education, $95(2)$, 103-105. 2006. https://doi.org/10.1002/j.2168-9830.2006.tb00882.x

[3] M. Borrego. "Conceptual difficulties experienced by trained engineers learning educational research methods". Journal of Engineering Education, 96(2), 91-102. 2007. https://doi.org/10.1002/j.2168-9830.2007.tb00920.x

[4] L.C. Benson, K. Becker, M.M. Cooper, O. Hayden Griffin and K.A. Smith. "Engineering education: Departments, degrees and directions". International Journal of Engineering Education, 26(5), 1042. 2010. Available at http://personal.cege.umn.edu/ smith/docs/Benson-EE-Dept-04 Ijee2359.pdf

[5] M.H.G. Murzi, M.P. Shekhar, and L.D. McNair. "Comparative Analysis of PhD programs in Engineering Education". 122nd ASEE Annual Conference \& Exposition, Seattle, WA. June 14-17, 2015. https://doi.org/10.18260/p.23707

[6] R.A. Streveler, N.P. Pitterson, A. Hira, H. Rodriguez-Simmonds, and J.O. Alvarez, J. O. (2015). "Learning about engineering education research: What conceptual difficulties still exist for a new generation of scholars?". In 2015 IEEE Frontiers in Education Conference (FIE) (pp. 1-6). IEEE. https://doi.org/10.1109/FIE.2015.7344303

[7] J.A. Siddiqui, C. Allendoerfer, R.S. Adams, and B. Williams. "Integration of scholarship: Interconnections among three studies on becoming an engineering education researcher". International Journal of Engineering Education, 32(6), $2352-2377 . \quad 2016$. https://www.researchgate.net/publication/347440175

[8] M. Leandro Cruz, G. N. Saunders-Smits, and P. Groen. "Evaluation of competency methods in engineering education: a systematic review." European Journal of Engineering Education 45.5 (2020): 729-757. https://doi.org/10.1080/03043797.2019.1671810

[9] J. Bernhard. "Engineering Education Research in Europe - coming of age", European Journal of Engineering Education, 2018 43:2, 167-170. https://doi.org/10.1080/03043797.2017.1412854

[10] M. Borrego and J. Bernhard. "The emergence of engineering education research as an internationally connected field of inquiry". Journal of Engineering Education, 100(1), 14-47. 2011. https://doi.org/10.1002/j.2168-9830.2011.tb00003.x

[11] B.K. Jesiek, M. Borrego and K. Beddoes. "Engineering Education Research: Global Trends and Collaborative Opportunities". In Research in Engineering Education Symposium (REES). Davos, Switzerland 7-10 July 2008. Permanent URL: https://www.researchgate.net/publication/236891313

[12] B. Williams, P. C. Wankat, and P. Neto. "Not so global: a bibliometric look at engineering education research", European Journal of Engineering Education 2016, vol. 43, no 2, p. 190-200 http://dx.doi.org/10.1080/03043797.2016.1153043

[13] E. L. Boyer, "Scholarship reconsidered: Priorities of the professoriate". Carnegie Foundation for the Advancement of Teaching. 1990.

[14] J. Bruner. “Toward a Theory of Instruction”. Cambridge, MA: Harvard University Press. 1966.

[15] R.M. Lima and D. Mesquita. "Engineering Education (Research) in European Countries-an overview based on publications in journals". In 2018 3rd International Conference of the Portuguese Society for Engineering Education (CISPEE) (pp. 1-6). IEEE. June 2018. https://doi.org/10.1109/CISPEE.2018.8593489

[16] D. Lopez and A. Llorens Garcia. Training needs for a PhD programme in Engineering Education. 2020 EDUCON - IEEE Ann. Eng. Ed. Conf. https://doi.org/10.1109/EDUCON45650.2020.9125286

[17] J. LaFrance, D. LaFrance, and T. D. Melton. "Chair Agency, Chair Preparation, and Academic Supports in Educational Leadership Doctoral Programs in the United States." International Journal of Doctoral Studies 15.1 (2020): 111-134. https://doi.org/10.28945/4507

[18] S. L. Ferguson, K. A. Hovey, and R. K. Henson. "Quantitative preparation in doctoral education programs: A mixed-methods study of doctoral student perspectives on their quantitative training." International Journal of Doctoral Studies (2017). https://doi.org/10.28945/3789

[19] J. Kittur, and S. Brunhaver. "Developing an Instrument to Measure Engineering Education Research Self-Efficacy." (2020). Paper presented at 2020 ASEE Virtual Annual Conference Content Access, Virtual On line. Permanent URL: https://peer.asee.org/34421

[20] I. Skakni. "Doctoral studies as an initiatory trial: expected and taken-for-granted practices that impede PhD students' progress." Teaching in Higher Education 23.8 (2018): 927-944. https://doi.org/10.1080/13562517.2018.1449742

[21] Woolston, Chris. "PhDs: the tortuous truth." Nature 575.7782 (2019): 403-407. https://doi.org/10.1038/d41586-019-03459-7

[22] A. Sverdlik, N.C. Hall, L. McAlpine, and K. Hubbard. "The PhD experience: A review of the factors influencing doctoral students' completion, achievement, and well-being." International Journal of Doctoral Studies 13.1 (2018): 361-388. https://doi.org/10.28945/4113

[23] J. Sinclair, R. Barnacle, and D. Cuthbert. "How the doctorate contributes to the formation of active researchers: What the research tells us." Studies in Higher Education 39.10 (2014): 1972-1986. https://doi.org/10.1080/03075079.2013.806460

[24] B. Durette, M. Fournier, and M. Lafon (2016) "The core competencies of PhD Studies" in Higher Education, 41:8, 1355-1370. https://doi.org/10.1080/03075079.2014.968540

[25] B. Adams, A. Arce-Trigatti, and P. Arce. "Understanding Learning Environments at the Graduate Level: A Theoretical Analysis of Doctoral Engineering Education Programs." ICERI2019 Proceedings, pp. 8924-8931. https://doi.org/10.21125/iceri.2019.2136

[26] E. Breitenbach. "Evaluating a model to increase doctorate program completion rates: A focus on social connectedness and structure." International Journal of Doctoral Studies 14.1 (2019): 217-236. https://doi.org/10.28945/4239 
[27] H. Ewing, K. Mathieson, J.L. Alexander, and J. Leafman. "Enhancing the acquisition of research skills in online doctoral programs: The Ewing ModelO"(2012) J. of Online Learning and Teaching, 8(1);34-44. Permanent URL: https://jolt.merlot.org/vol8no1/ewing 0312.htm

[28] R. J. Coe, M. Waring, L. V. Edges and J. Arthur, eds., "Research Methods and Methodologies in Education". Thousand Oaks: California. 2012.

[29] L. Cohen, L. Manion and K. Morrison. "Research Methods in Education". 8th Edition. Routledge 2018.

[30] J. W. Creswell and T. C. Guetterman. "Educational Research: Planning, Conducting, and Evaluating Quantitative and Qualitative Research", 6th Edition. Pearson 2019.

[31] J. Heywood. "Engineering Education. Research and Development in Curriculum and Instrution". IEEE press 2005.

[32] C.C. Johnson, M. J. Mohr-Schroeder, T.J. Moore, and L.D. English eds. "Handbook of Research on STEM Education". Routledge 2020.

[33] M. Q. Patton "Qualitative Research \& Evaluation Methods. Integrating Theory and Practice". 4th edition. Sage Publishing 2015.

[34] M. Tight. "Higher Education Research. The Developing Field". Bloomsbury Publishing. 2019. 